\title{
Density Spectral Array of BIS VISTA Monitoring System in Epilepsy Surgery with Intraoperative Electrocorticography
}

L. Bosch, L. Castelltort, M. Lamora, E. Lopez Argüello, J. Fernández-Candil, S. Pacreu Department of Anaesthesiology. Parc de Salut Mar. Barcelona. Spain

\section{Introduction}

The Bilateral Bispectral Index (BIS) was designed to allow the user to record and display four channels of EEG; two from each side of the brain. This monitor equally shows changes in the power spectrum distribution through the Density Spectral Array (DSA) ${ }^{1}$. Asymmetry is a processed variable indicating the percentage of EEG power present in left or right hemispheres with respect to total (left and right) EEG power ${ }^{2}$. In our case BIS was used to observe changes in DSA, during the anesthetic-surgical procedure.

\section{Case report}

A 51-years-old man underwent left amigdalohipocampectomy 3 years ago for drug resistant epilepsy. However, he continued with epileptic crisis and he was scheduled for left temporal lobectomy with intraoperative electrocorticography. On entering the operating room, the electrocardiogram, non invasive blood pressure and the percentage oxygen saturation were monitored. Bilateral BIS electrode strip was placed on the front temporal position according to the International 10-20 system of electrode placement. Anaesthesia was maintained with sevoflurane (MAC 0.5) and infusions of remifentanyl $(0.06 \mathrm{mcg} / \mathrm{kg} / \mathrm{min})$ and dexmedetomidine $(0.5 \mathrm{mcg} / \mathrm{kg} / \mathrm{h})$ to keep BIS values within 45-60 range. Rocuronium was also administered $(0.3 \mathrm{mg} / \mathrm{kg} / \mathrm{h})$. During surgery, an asymmetry was detected related to the left hemisphere, where the epileptogenic focus was (Fig. 1A). This asymmetry was a consequence of a power increase in low frequency $(0.1-4 \mathrm{~Hz})$ and alpha bands $(8-12 \mathrm{~Hz})$.

Before performing the intraoperative electrocorticography, sevoflurane and remifentanyl infusion rates were slowed resulting in light anesthesia, which caused a decrease of power in low frequency and alpha bands, more visible in the right side (Fig. 1A). When the surgery finished, sevoflurane was increased (MAC 0.6) and the effect of "fill-in" of sevoflurane on the spectrogram appeared, increasing the power on the left hemisphere (Fig. 1B). Unlike DSA, the BIS trend did not reflect differences between two hemispheres. The patient was extubated in the operating room and transferred to the recovery room. He was discharged from hospital two days later.
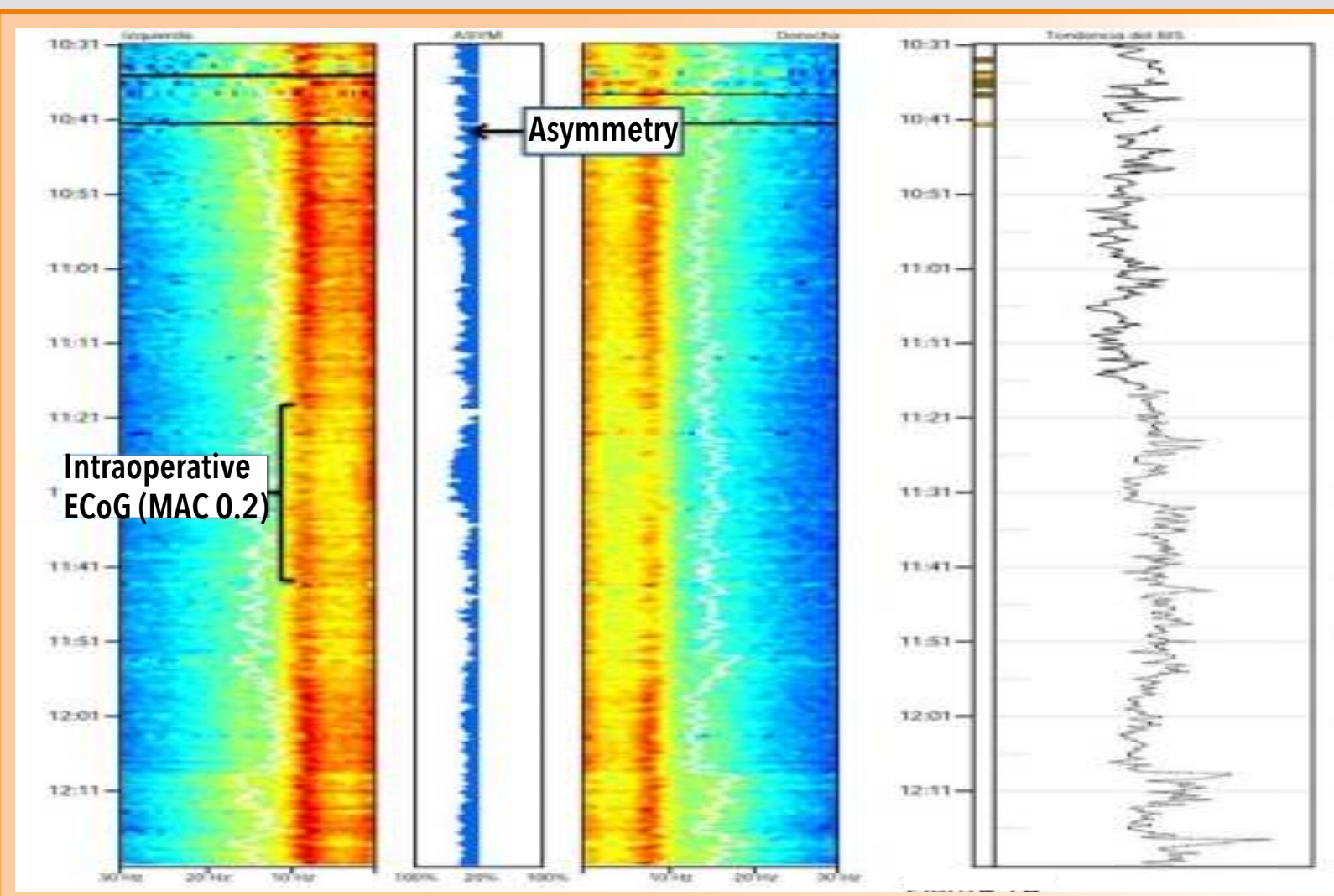

Fig. 1A.

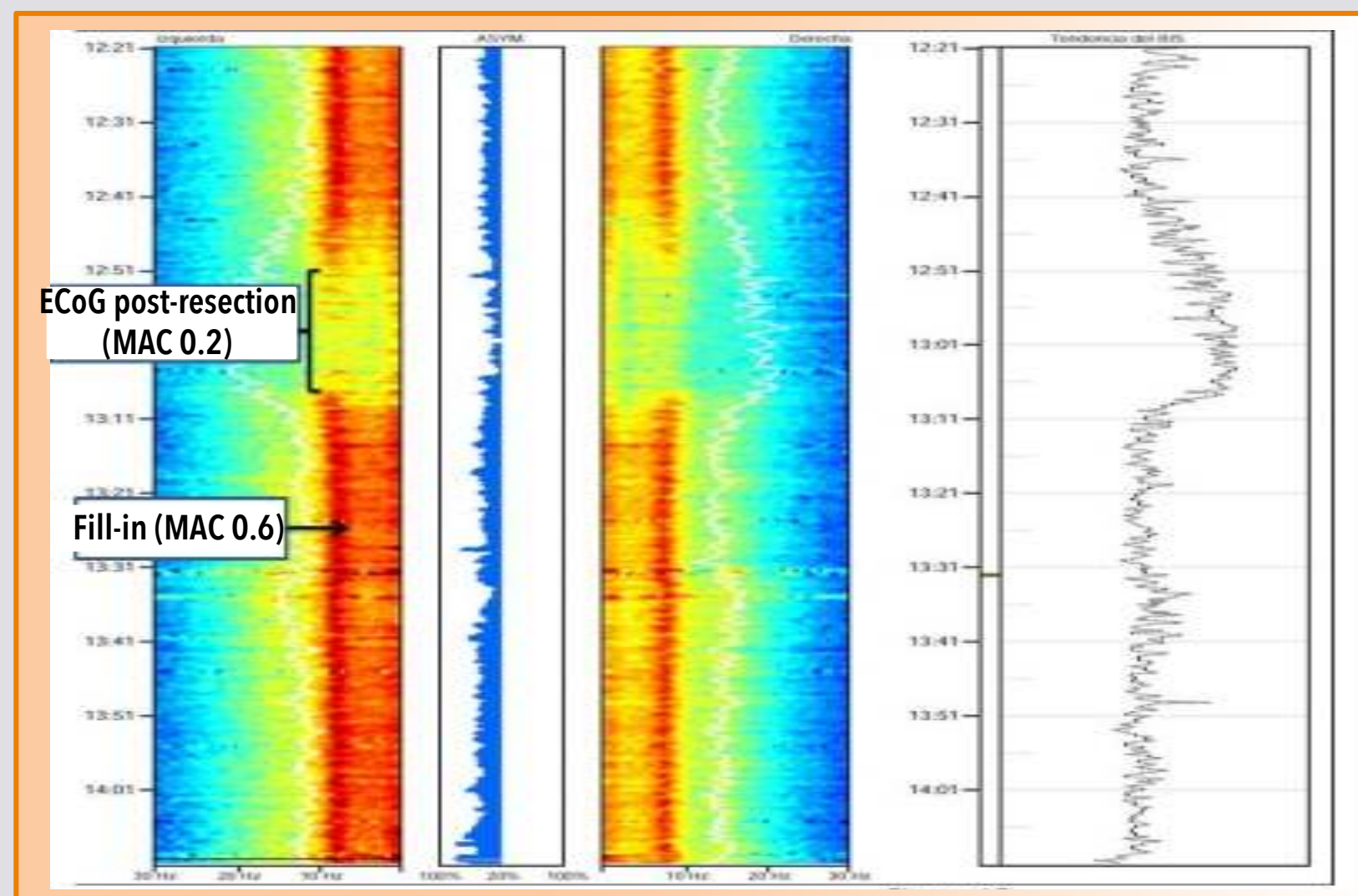

Fig. 1B.

\section{Discusion}

This case provides novel evidence to support the clinical utility of DSA in monitoring depth of anaesthesia and sedation. As described by Purdon, every anesthetic has its own spectrogram².

\section{References}

1. Hernández-Hernández MA, et al. Utilidad de la matriz de densidad espectral del sistema de índice biespectral bilateral en la monitorización del status epilepticus no convulsivo. Med Intensiva. 2014, May;38(4):265-7. 